\title{
PERANCANGAN SISTEM PENGATURAN PADA SISTEM PELUMASAN DAN TRIP OIL TURBIN GAS PT.PLN (PERSERO) SEKTOR PEMBANGKITAN BELAWAN
}

\author{
M.Sabri ${ }^{1}$, Nasri sarah Siregar ${ }^{1}$. \\ ${ }^{1}$ Universitas Sumatera Utara (USU) \\ E-mail : m.sabri@usu.ac.id
}

\begin{abstract}
ABSTRAK
Turbin Gas pada suatu Pembangkit Listrik memiliki banyak sistem yang mempengaruhi kerja turbin, sedikit saja terjadi kesalahan pada sistem akan dapat berakibat fatal dan merusak sistem kerja pada turbin, ada banyak sekali sistem yang terdapat pada sebuah pembangkit listrik, salah satunya adalah sistem pelumasan yang merupakan suatu sistem yang mengatur pelumasan komponen-komponen yang bergerak dalam turbin serta peralatan pendukung lainnya, serta menyediakan oli untuk digunakan sebagai penggerak aktuator pada variable geometry control system. Sistem ini mengatur agar fungsi pelumasan secara kontinyu pada gas turbine agar dapat berjalan dengan maksimal.

Pada penelitian ini penulis akan membahas tentang sistem pelumasan dalam bentuk blok sistem kontrol speedtronik yang akan di simulasikan dengan software Matlab-simulink dengan parameter suhu dan waktu menggunakan blok diagram dengan metode sistem orde1 , transfer fungsi dan sistem pengontrolan PI yaitu $\mathrm{Kp}=10$ dan $\mathrm{Ki}=1$, serta akan di tambahkan switch relay dengan masukan temperatur minimum dan maximum untuk melihat peforma sistem pelumasan selama bekerja dan mengalami shutdown maka dilakukan simulasi dengan beberapa asumsi dan hasilnya dilihat pada grafik yang di hasilkan oleh simulink, lalu grafik tersebut akan di bandingkan dengan sistem yang telah ada.
\end{abstract}

Kata kunci: Turbin Gas, Sistem Pelumasan, Simulink, MATLAB.

\begin{abstract}
Gas Turbines in a Power Plant have many systems that affect the performance of the turbine, a slightest error in the system can be fatal which will cause a damage to the working system of the turbine, there are many systems contained in a power plant, one of which is the lubrication system that regulates the lubrication of the moving components in the turbines and other supporting equipment, as well as to provide oil to be used as actuators drive on geometry control system variable. This system regulates the continuous lubrication function of the gas turbine to run optimally.

In this study the author will discuss the lubrication system in the form of a speedtronic control system block which will be simulated with Matlab-simulink software with temperature and time parameters using diagrams block $w$ ith order-1 system methods, the function transfers and PI control systems namely $\mathrm{Kp}=10$ and $\mathrm{Ki}=1$, with an addition of $a$ relay switch with an input of minimum and maximum temperature to see the performance of the lubrication system during work and having a shutdown then to simulate with assumptions and the results can be seen in the graph produced by simulink, only then the graph will be compared with existing system.
\end{abstract}

Keywords: Gas Turbine, Lubrication System, Simulink, MATLAB.

\section{I.PENDAHULUAN}

Pembangkit listrik tenaga gas merupakan salah satu produsen listrik yang di andalkan untuk dapat memenuhi kebutuhan energi listrik di indonesia. Kestabilan sangat di butuhkan pada pembangkit listrik sehingga sistem pengendalian digunakan untuk menjaga variable proses 
tersebut tetap stabil, salah satunya dengan melakukan pengendalian sistem kontrol pada turbin pembangkit listrik.

Temperatur turbin gas harus di jaga kestabilannya agar keluaran daya listrik berjalan dengan baik, secara keseluruhan sistem pada PLTG sudah dilengkapi dengan sistem speedtronik yaitu sistem yang mengontrol dan memproteksi turbin gas, simulasi sistem kontrol speedtronik pada Matlab-simulink ini diharapkan dapat memberikan wawasan sebagai bahan pertimbangan dalam penelitian selanjutnya.

\section{Tinjauan Pustaka}

\section{Turbin Gas}

Turbin gas adalah suatu penggerak mula yang memanfaatkan gas sebagai fluida kerja. Didalam turbin gas energi kinetik dikonversikan menjadi energi mekanik berupa putaran yang menggerakkan roda turbin sehingga menghasilkan daya. Bagian turbin yang berputar disebut rotor atau roda turbin dan bagian turbin yang diam disebut stator atau rumah turbin. Rotor memutar poros daya yang menggerakkan beban (generator listrik, pompa, kompresor atau yang lainnya). Turbin gas merupakan salah satu komponen dari suatu sistem turbin gas. Sistem turbin gas yang paling sederhana terdiri dari tiga komponen yaitu kompresor,ruang bakar dan turbin gas.

\section{Sistem Pelumasan}

Adalah suatu sistem yang mengatur pelumasan komponen-komponen yang bergerak dalam turbin serta peralatan pendukung lainnya, serta menyediakan oli untuk digunakan sebagai penggerak aktuator pada variable geometry control system. Sistem ini mengatur agar fungsi pelumasan secara kontinyu pada gas turbine agar dapat berjalan dengan maksimal.

Pada saat stanby, melalui heater yang di pasang dalam tangki minyak pelumas, kekentalan minyak pelumas dijaga agar tetap pada viskositas yang di perlukan untuk star-up turbin. Temperature switch memantau temperatur tangki dan mengontrol heater untuk menjaga agar temperatur minyak pelumas mencapai harga yang di perlukan untuk mendapatkan viskositas yang di izinkan. Temperatur switch lainnya memantau temperatur minyak dalam tangki dan tidak akan memberikan izin start turbin apabila temperatur minyak berada dibawah temperatur yang di perlukan untuk mendapatkan viskositas yang sesuai.

\section{Propotional Integral (PI)}

PI merupakan kontroller untuk menentukan presisi suatu sistem instrumentasi dengan gabungan aksi kendali proporsional dan aksi kendali integral membentuk aksi kendali proporsional integral (kendali PI). Gabungan aksi ini mempunyai keunggulan dibandingkan 
dengan masing-masing penyusunnya. Keunggulan utamanya adalah diperolehnya keuntungan dari masing-masing aksi pengendali dan kekurangan yang satu dari aksi pengendali dapat diatasi. Dengan kata lain elemen- elemen pengendali P dan I secara keseluruhan bertujuan untuk mempercepat reaksi sebuah sistem dan menghilangkan offset . Rumus sinyal keluaran pengendali PI dapat dinyatakan dalam Persamaan berikut :

$$
C_{p}=K_{p}\left(e(t)+\frac{1}{T i} \int e(t) d t\right)
$$

Dimana:

$\mathrm{C}_{0}=$ sinyal keluaran pengendali PI

\section{Speedtronik}

Sistem Speedtronik adalah sistem kontrol elektronik yang menyediakan sinyal-sinyal analog dan digital yang diperlukan untuk mengontrol dan memproteksi pengoperasian Turbin Gas. Kondisi operasi Turbin Gas di pergunakan sebagai sinyal-sinyal umpan balik ( feed back) ke sistem kontrol speedtronik.

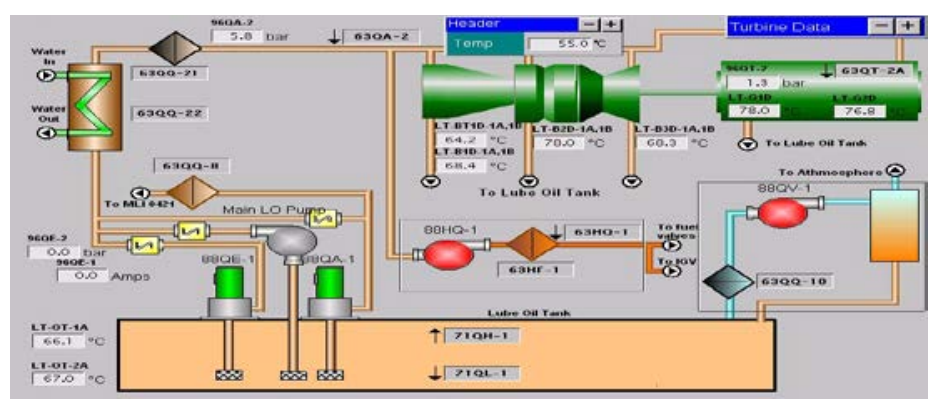

Gambar 1. Monitoring sistem pelumasan speedtronik

\section{Simulasi Kontrol Turbin Menggunakan MATLAB/Simulink}

Proses perancangan simulasi sistem kontrol dilakukan dengan identifikasi parameter hingga memasukannya kedalam blok diagram Matlab-simulink sehingga menghasilkan keluaran yang sesuai dengan sistem speedtronik, Adapun langkah-langkah proses perancangan simulasi sistem kontrol sebagai berikut :

\section{Identifikasi Parameter}

Langkah awal dalam proses simulasi untuk membangun sistem kontrol Turbin yaitu dengan mengubah persamaan matematik dari sistem kontrol turbin kedalam bentuk blok-blok diagram yang telah disediakan Simulink.

Tabel 1. Parameter temperatur dan waktu

\begin{tabular}{|l|c|}
\hline Bukaan katup & Waktu \\
\hline
\end{tabular}




\begin{tabular}{|l|l|}
\hline 78,0 & $10: 40$ \\
\hline 70,8 & $10: 45$ \\
\hline 65,8 & $11: 03$ \\
\hline
\end{tabular}

Pertama-tama di lakukan perhitungan dalam mencari fungsi alih pada sistem tersebut dengaan menggunakan metode sistem orde 1. Pendekatan masalah di lakukan dengan menganalisis secara khusus cakupan fungsi alih dari data menggunakan metode estimasi parameter yaitu progresive integration methode. Pertama tentukan fungsi alih terlebih dahulu seperti perhitungan di bawah ini :

$$
\begin{gathered}
\frac{Y(s)}{X(s)}=\frac{K}{t s+1} \\
K=\lim _{t \rightarrow \infty} y(t)=\lim _{s \rightarrow 0} s Y \\
K=\lim _{s \rightarrow 0} s \frac{K}{s(t s+1)}
\end{gathered}
$$

Maka,

$\mathrm{K}=$ keluaran $\mathrm{y}(\mathrm{t})$ pada steady state, atau

$\mathrm{K}=\mathrm{C}$ (kondisi steady state)- $\mathrm{C}_{0}$

Untuk memperoleh $\mathrm{t}$

$$
\begin{gathered}
\frac{Y(s)}{X(s)}=\frac{K}{t s+1} \\
t s Y+Y(s)=K X(s)
\end{gathered}
$$

Jika persamaan di-invers dalam bentu Laplace dan semua kondisi awal adalah nol, maka dapat di peroleh :

$$
t \frac{d y(t)}{d t}+y(t)=\mathrm{Kx}(\mathrm{t})
$$

Untuk $\mathrm{x}(\mathrm{t})=1$ dan semua kondisi awal adalah 0

$$
\begin{gathered}
t \frac{d y(t)}{d t}+y(t)=(\mathrm{K}-\mathrm{y}(\mathrm{t})) \mathrm{dt} \\
\int\{t d y(t)\}=\int\left\{K\left(1-\frac{y(t)}{K}\right) d t\right\} \\
t y(t)=K \int_{0}^{1}\left\{1-\frac{y(t)}{K}\right\} d t
\end{gathered}
$$

Lalu di ambil

$$
d(t)=1-\frac{y(t)}{K}, s(t)=\int_{0}^{t} d(t) d t, t=\frac{K s(t)}{y(t)}
$$

Pada kondisi steady state, $\mathrm{K}$ sama dengan $\mathrm{y}(\mathrm{t})$ sehingga

$$
\lim _{t \rightarrow \infty} s(t)
$$


Berdasarkan persamaan yang telah di peroleh dan data yang ada, maka untuk mencari fungsi alih adalah dengan memasukkan nilai-nilai tersebut, dimana :

$$
\mathrm{Y}=\mathrm{C}_{1}-\mathrm{C}_{0}
$$

Maka,

$\mathrm{Y}(0)=78,9-78,9=0$

$\mathrm{Y}(1)=70,8-78,9=-8,1$

$\mathrm{Y}(2)=69,8-78,9=-9,1$

$\mathrm{Y}(3)=68,8-78,9=-10,1$

Kemudian delay $=\frac{\sum t}{n}=\frac{10,40-11,03}{3}=\frac{23}{3}=7,7$ menit

$\mathrm{K}=\mathrm{C}$ (kondisi steady state) $-\mathrm{C}_{0}=68,8-78,9=-10,1$

$d=1-\frac{y}{K}$

Maka hasilnya adalah,

$\mathrm{d}(0)=1-\frac{y}{K}=1$

$\mathrm{d}(1)=1-\frac{y(1)}{K}=0,199$

$\mathrm{d}(2)=1-\frac{y(2)}{K}=0,1$

$\mathrm{d}(3)=1-\frac{y(3)}{K}=0$

lalu jumlahkan d dan mencari $\mathrm{t}$

$$
\sum(d)=d(0)+d(1)+d(2)+d(3)=1+0,199+0,1+0=1,35
$$

$t=\operatorname{delay} x \sum(d)=7,7 \times 1,356=10,0023$

Dari nilai-nilai yang telah diperoleh, dapat ditentukan bahwa fungsi alih dari bukaan katup temperatur oli adalah :

$$
\frac{Y(s)}{X(s)}=G(s)=\frac{K}{t s+1}=\frac{-10,1}{10,0023}
$$

\section{Membangun Model}

Langkah kedua adalah membangun model sistem kontrol, model sistem kontrol turbin dibangun sesuai dengan persamaan matematik dari sistem. Persamaan matematik tersebut kemudian dibangun menjadi blok-blok diagram, input, output, serta parameter-parameter yang berhubungan dengan sistem kontrol turbin, setelah di dapatkannya nilai dari transfer fungsi dan PI maka nilai tersebut akan di masukan ke dalam Bok diagram simulink. 


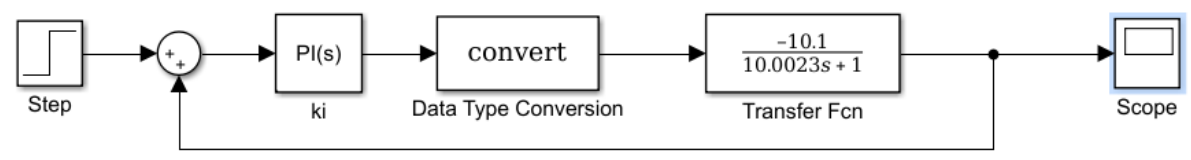

Gambar 1. model simulasi sistem pelumasan

\section{Pemasukan Parameter}

Lagkah ketiga yang dilakukan adalah proses pemasukan parameter sistem kontrol turbin dan parameter simulasi yang diinginkan. Parameter yang dimasukkan yaitu sesuai dengan persamaan matematik dari sistem kontrol turbin dan memasukkan nilai dari parameterparameter sistem kontrol turbin yang berhubungan agar simulasi bejalan sesuai dengan yang dibutuhkan.

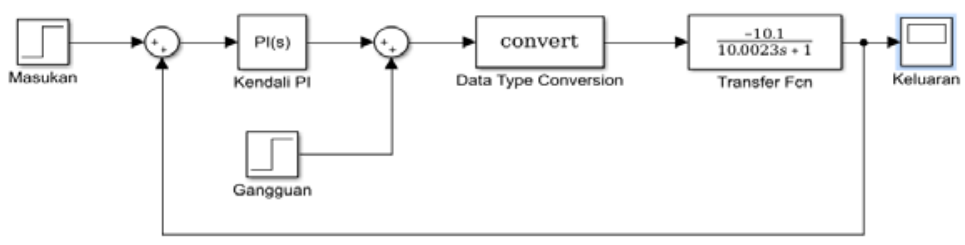

Gambar 2. Diagram blok simulasi sistem keseluruhan dengan pengendali PI yang di beri gangguan

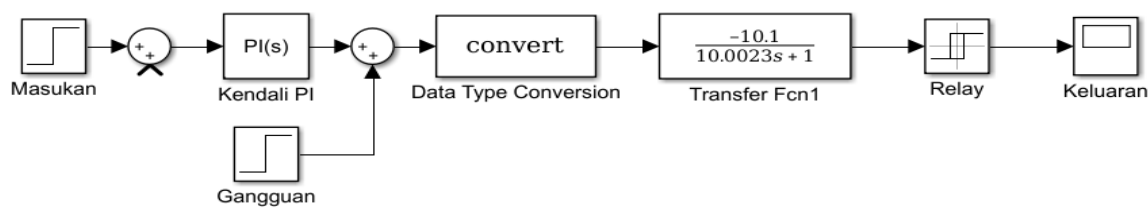

Gambar 3. Diagram blok simulasi sistem keseluruhan dengan pengendali PI yang di beri gangguan dan diberi relay.

\section{Hasil dan analisa}

Pembahasan pada penelitian ini dilakukan dengan merancang dan menjalankan simulasi terhadap sistem pelumasan speedtronik, Pada penelitian ini sistem kontrol tersebut akan di simulasikan dengan menggunakan Software Matlab-Simulink. 


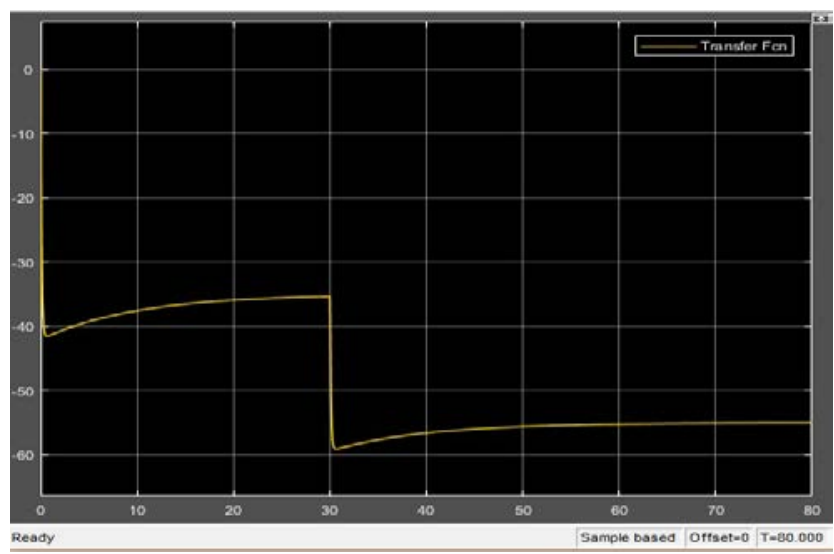

Gambar 4 Hasil simulasi sistem keseleruhan pengendali dengan gangguan

Gambar 4 nilai awal gangguan akan di set sebesar $70^{\circ} \mathrm{C}$ dan set akhir temperatur di set pada $110^{\circ} \mathrm{C}$, konstanta pengendalinya adalah $\mathrm{kp}=10$ dan $\mathrm{ki}=1$.

Dapat dilihat juga bahwa sistem mengalami overshoot temperatur sampai $42^{\circ} \mathrm{C}$ tetapi sistem akan kembali menuju steady state secara otomatis, lalu pada detik ke 30, set point di ubah ke $110^{\circ} \mathrm{C}$ atau 2 kali dari set point atau $55^{\circ} \mathrm{C}$ dan sistem kembali mengalami overshoot temperatur hingga $59^{\circ} \mathrm{C}$, tetapi sistem stabil kembali setelah 30 detik dari gangguan pertama.

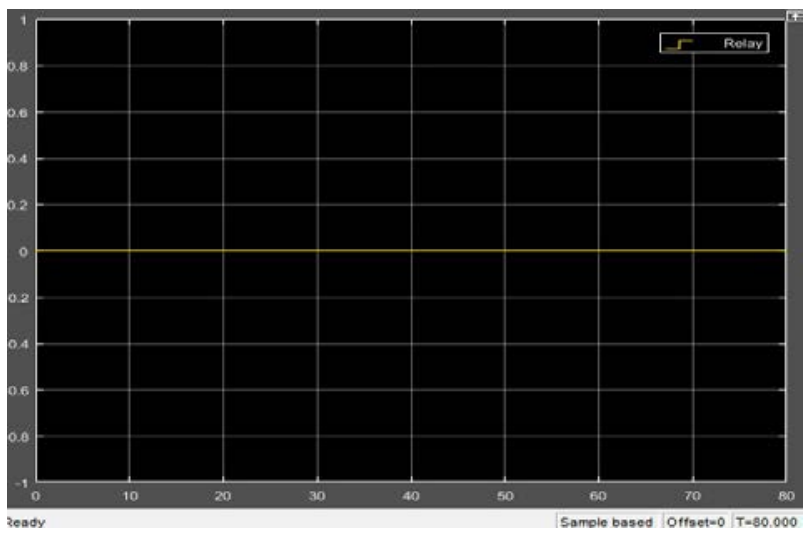

Gambar 5 Hasil simulasi sistem keseluruhan dengan pengendali yang di beri gangguan dan di beri relay

Pada gambar 5. menunjukkan bahwa ketika diberi pengendali Relay grafik menunjukan kondisi mati ketika turbin diberi gangguan, sistem menangapi dengan cepat simulasi berjalan dengan baik. Nilai kendali PI dari hasil simulasi tersebut tidak mutlak harus sama dengan realisasi jika diaplikasikan di lapangan. Nilai nya dapat di atur agar dapat respon paling ideal dimana time respone cepat, overshoot rendah dan waktu yang di butuhkan untuk menuju steady state juga cepat, karena berbeda karakteristik akan berbeda nilai pengendaliannya.

\section{Perbandingan Hasil Simulasi}


Setelah simulasi selesai maka hasil akhirnya akan di bandingkan dengan sistem speedtronik pada PT.PLN (Persero) Sektor Pembangkitan Belawan. Terlihat bahwa hasil simulasi sesuai dengan sistem speedtronik, sistem yang mengalami gangguan akan mengalami overshoot temperatur pada keadaan awal namun akan perlahan-lahan menuju steady state dengan keadaan normal, dan ketika turbin mengalami overshoot berlebih dan harus segara mematikan turbin maka di beri relay dan hasilnya turbin akan segera trip/shootdown, sistem tersebut sesuai dengan sistem sistem pelumasan dan trip oil yang ada pada sistem speedtronik.

Tabel 2. Perbandingan Hasil Simulasi

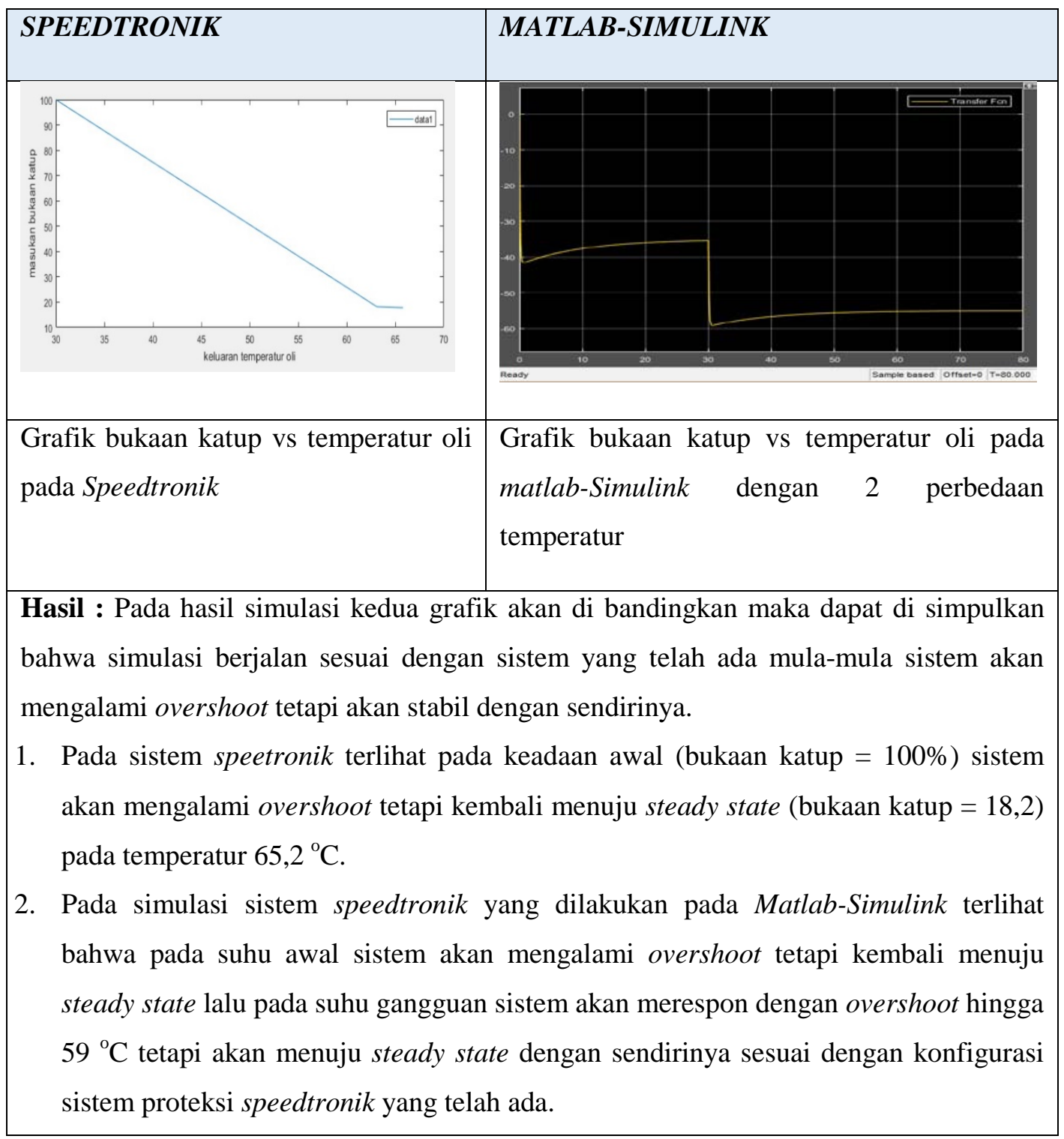


3. Sistem akan merespon setelah 30 detik dari gangguan.

\section{KESIMPULAN}

Berdasarkan simulasi yang telah dilakukan terhadap sistem kontrol turbin trip dapat diambil kesimpulan yaitu sebagai berikut :

Kontrol kinerja turbin gas terhadap sistem pelumasan oli dari sistem kontrol speedtronik disimulasikan dengan simulink. Dari simulasi yang dihasilkan, pengontrol berfungsi dengan baik sesuai performa kendali yang dibangun secara eksperimen di PLTGU LOT III pembangkit listrik tenaga gas PT. PLN (Persero) Sektor Pembangkitan Belawan Pulau Sicanang.Medan Sumatera Utara.

Fungsi alih yang didapatkan dalam perhitungan metode Orde 1 dengan menggunakan data sistem pelumasan pada PT.PLN (Persero) Sektor Pembangkitan belawan adalah sebesar G(s) = $\frac{-10,1}{10,0023}$ yang akan menghubungkan antara masukan dan keluaran pada simulasi sistem kontrol sistem pelumasan turbin gas.

Simulasi sistem kendali dilakukan terhadap 2 sistem keduanya ialah sistem proteksi speedtronik diubah kedalam Software Matlab-simulink diantaranya merupakan sistem pelumasan gas turbin dan sistem trip turbin dengan diberinya relay. dari hasil simulasi menunjukkan ketika turbin diberi relay maka sistem menanggapi dengan cepat dan turbin akan otomatis mematikan turbin (trip/shutdown) .

\section{DAFTAR PUSTAKA}

[1] Arismunar,Wiranto.Pengantar turbin Gas dan Motor Propulsi. Penerbit ITB. Bandung.

[2] Training Operator dan Regu Pemeliharaan PLTG 1X120 MW.PT.PLN (Persero) Sektor Pembangkitan Belawan. Belawan 2009

[3] Dietzel, F.. Turbin,Pompa, dan Kompresor. Edisi ke-3. Penerbit Erlangga.Jakarta 1992.Hal 153

[4] http://id.m.wikipedia.org/wiki/Sistem_kendali

[5] Frans Gunterus. 1997. Falsafah Dasar: Sistem Pengendalian Proses. Bandung: Pt.Gramedia.

[6] Jinghua, Zhong. 2006. PID Controller Tuning: A Short Tutorial. Mechanical Engineering, Purdue Univrersity

[7] Ir. Zahiful Bahri, Ir. Windalina Syafiar, Ir. Syukri Abdullah, Ir. Rahman Hasibuan, Ir. Syamsir A min. Process Control And Instrumentation . PT. ARUN NGL 1983

[8] Sawyer, John W. 1976. Gas Turbin Engineering Handbook. Second Edition Volume 1 of Three Volume. Gas tutbin Publication, INC, USA.

[9] Laboratorium Teknik Pengaturan versi 2005 
[10] https;//id.m.wikipedia.org/wiki/Simulink

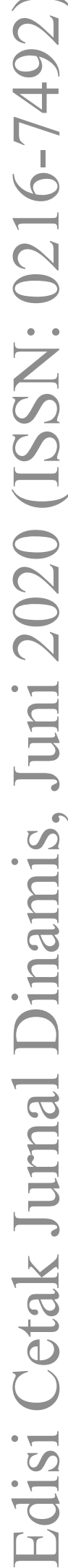

